\title{
Effect of Variations in Body Mass Index on Serum Leptin Levels in Pre and Post Menopausal Women
}

\author{
Abdul Khaliq Naveed, Tausif Ahmed Rajput \& Nasir Mahmood \\ Department of Biochemistry \& Molecular Biology, Army Medical College \\ National University of Sciences \& Technology (NUST), Rawalpindi, Pakistan \\ Tel: 92-321-505-1950Ｅ-mail: Khaliqnaveed2001@yahoo.com \\ Maujid Masood Malik \\ Department of Biochemistry, Foundation University Medical College \\ Rawalpindi, Pakistan \\ Fatahiya Kashif \\ Department of Biochemistry \& Molecular Biology, Army Medical College \\ National University of Sciences \& Technology (NUST), Rawalpindi, Pakistan
}

\begin{abstract}
Objective: To measure the serum leptin and insulin levels and assess that how body mass index and affects these levels in pre and post menopausal obese and non-obese women.

Place and duration of study: It was a comparative study. Sampling was done from various Hospitals, organizations and residential areas. The experimental work was carried out at the department of Biochemistry \& Molecular Biology and Center for Research in Experimental and Applied Medicine-1 (CREAM-1), NUST, Rawalpindi, Pakistan and was spread on duration of 18 months.
\end{abstract}

Methodology: The samples for the study were obtained from healthy eighty subjects \& divided into premenopausal and postmenopausal groups of 40 each which were further sub-divided into obese and non obese based on the body mass index (cutoff BMI value $=25 \mathrm{~kg} / \mathrm{m}^{2}$ ). Fasting blood sugar, triglycerides, serum Insulin and serum leptin were measured along with BMI and HOMA IR. Data was analyzed for frequencies, percentages, means and standard deviation $( \pm \mathrm{SD})$. The Chi-square test was used for comparison of qualitative data variables between groups, while the Student's t-test was used for comparison of means. Linear correlations were performed by using the Pearson's Correlation Coefficient, $r$.

Results: There is significant difference in the mean age, weight, BMI and insulin between the two non-obese groups. A significant difference in the mean age and triglyceride between the two obese groups was also observed. There is significant difference in the mean age, weight and BMI between the pre menopausal non-obese and obese groups along with a significant difference in the mean weight, BMI, insulin and HOMA IR between the postmenopausal non-obese and obese groups. Leptin has significant positive correlation with weight, BMI, and HOMA IR whereas Insulin has significant positive correlation with weight, leptin and HOMA IR.

Conclusion: Menopause does not influence FSL levels. The variations observed in FSL levels between pre and postmenopausal women, in some studies, might be due to differences in their mean FSI levels and BMI. The mean FSL tends to increase with increased BMI irrespective of menopausal status. There is corresponding increase in FSL with increase in FSI levels, generally the obese have higher FSI and FSL levels, irrespective of menopausal status. Major metabolic hormones insulin and leptin, don't seem to have a role in pathophysiology of postmenopausal obesity.

Keywords: Leptin, Insulin, Triglycerides, BMI, HOMA IR

\section{Introduction}

The postmenopausal status confers a number of significant risk factors for women, as women ages, their risk of heart disease rises. Coronary artery disease rates in women after menopause are 2-3 times higher than in women of the same age before menopause. Leptin and Insulin are two major metabolic hormones that affect body fat 
mass and predispose to obesity. The exact role of these two hormones in the pathophysiology of postmenopausal obesity has not been identified. BMI has been considered as a gold standard for defining overweight and obesity; it has correlated with percentage body fat (Bhansali et al., 2006). BMI has a positive correlation with serum leptin levels (Injuin et al., 1999). Moreover leptin in the physiological range serves as a regulator of cardiovascular function, whereas elevated leptin levels may act as a pathophysiological trigger for cardiovascular disease. Due to its prothrombotic and angiogenic effects, as well as its inverse relation with high density lipoprotein (HDL), leptin is believed to have etiological role in ischemic heart disease (Jaleel et al., 2006). In some studies post menopausal women have been observed to have increased leptin levels (Gomez et al., 2003). However, most studies conclude that menopause does not influence the serum leptin levels (Douchi et al., 2002) because of its positive correlation with BMI and serum insulin levels, it can be postulated that variations in body mass index and insulin levels are responsible for this discrepancy. Insulin secretion is two to three times higher in obese individuals (Champe et al., 1994).Variability in insulin levels contributes to variations in leptin levels independently from the influence of adiposity in both men and women. In individuals of identical adiposity level, high fasting insulin is associated with elevated leptin levels (Doucet et al., 2000). The pathophysiology of leptin resistance is comparable to that of insulin resistance, both develop at receptor level and both are positively related to obesity.

The present study has been designed to measure the serum leptin and insulin levels in pre and post menopausal obese and non-obese women in order to assess how body mass index and insulin affect the leptin levels of pre and post menopausal women. To date not enough relevant studies have been done in Pakistan on the role of these hormones in causing postmenopausal obesity and aggravating the risk for CAD in this group of people. The present study may help to provide guidelines for possible remedies for postmenopausal women.

\section{Methods}

It was a comparative study, comparing pre and postmenopausal women, further divided into obese and non-obese groups. The sample for the study was generated from healthy women of Rawalpindi / Islamabad and surroundings. They included volunteers from healthy attendants of patients at Military Hospital Rawalpindi, school teachers from various schools, women from various vocational and welfare organizations, and various residential areas. Subjects were divided into four groups: Non obese premenopausal ( $\mathrm{n}=20)$, Obese premenopausal $(n=20)$, Non-obese postmenopausal $(n=20)$ and Obese postmenopausal $(n=20)$.

Early morning fasting whole blood samples (about $5.5 \mathrm{ml}$ ) were obtained. $1.5 \mathrm{ml}$ blood was transferred into orange capped sodium EDTA tubes for estimation of fasting blood sugar. $4 \mathrm{ml}$ blood was transferred into Venoject ${ }^{\circledR}$ evacuated blood collection tubes (Terumo Europe N. V., Interleuvenlaan 40, 3001 Leuven, Belgium). The blood was allowed to clot at room temperature for 30 minutes. The clotted blood was centrifuged at room temperature for 15 minutes, within one hour of collection. The serum was separated, about $0.5 \mathrm{ml}$ was used to measure fasting triglyceride level, and the rest of the serum was transferred into separate aliquots. Samples were labeled, dated and stored at $-20^{\circ} \mathrm{C}$ until measurement.

Biochemical test of Fasting blood sugar \& fasting triglycerides were performed by commercially available kits on Slectra Autoanalyzer. Fasting serum insulin and fasting serum leptin were performed using DRG insulin ELISA kit (solid phase enzyme-linked-immunosorbent assay based on sandwich principle). Fasting serum insulin was estimated: The microtiter wells are coated with a monoclonal antibody directed towards a unique antigenic site on the insulin molecule. An aliquot of patient sample containing endogenous insulin is incubated in the coated well with enzyme conjugate, which is an anti-insulin antibody conjugated with Biotin. After incubation the unbound conjugate is washed off. During the second incubation step Streptavidin Peroxidase Enzyme Complex binds to the biotin-anti-insulin antibody. The amount of bound Horseradish peroxidase (HRP) complex is proportional to the concentration of insulin in the sample. Having added the substrate solution, the intensity of color developed is proportional to the concentration of insulin in the patient sample which is measured by recording the optical density at $450 \pm 10 \mathrm{~nm}$ with a micro titer plate reader within 10 minutes. Fasting serum leptin was estimated: The microtiter wells are coated with a monoclonal antibody directed towards a unique antigenic site on the leptin molecule. An aliquot of patient sample containing endogenous leptin is incubated in the coated well with a specific rabbit anti-leptin antibody. A sandwich complex is formed. After incubation the unbound material is washed off and an anti rabbit peroxidase conjugate is added for detection of the bound leptin. Having added the substrate solution, the intensity of color developed is proportional to the concentration of leptin in the patient sample which is measured by recording the optical density at $450 \pm 10 \mathrm{~nm}$ with a micro titer plate reader within 10 minutes.

Statistical analysis was performed with use of computer program SPSS version 10.0 analyzed for frequencies, 
percentages, means and standard deviation $( \pm \mathrm{SD})$. The Chi-square test was used for comparison of qualitative data variables between groups, while the Student's t-test was used for comparison of means. Statistical significance was accepted as $\mathrm{p} \leq 0.05$. Linear correlations were performed by using the Pearson's Correlation Coefficient, $r . \mathrm{p} \leq 0.05$ was considered significant.

\section{Results}

Frequency distribution of demographic data, biochemical data, demographic and biochemical indices is representative of women in the age range of 18-89years, their heights range from 1.4-1.7m, they include underweight, normal weight, and obese women, their fasting blood glucose and triglyceride are in the normal range. There is wide variation in the frequency distribution of fasting serum insulin, leptin and HOMA IR. There is statistically significant difference in the distribution of age $(p<0.001)$, heights $(p \leq 0.025)$ and fasting blood sugar $(\mathrm{p} \leq 0.05)$ between the pre and postmenopausal groups. Postmenopausal having greater heights and higher values of fasting blood glucose. The difference in age distribution is as expected. There is significant difference in the distribution of weights among obese and non-obese groups $(p \leq 0.01)$. There is significant difference in the distribution of fasting blood glucose among the post menopausal obese and non-obese groups $(\mathrm{p} \leq 0.04)$. Serum insulin, leptin and HOMA IR are not normally distributed. Presence of outliers makes the data skewed. Figure I, figure II and figure III shows the histograms of serum insulin, serum leptin and insulin resistance index (HOMA IR) with and without outliers respectively.

A descriptive statistics shows means, \pm SD and student's t-test of demographic and biochemical variables of four study groups in Table I and table II along with figure IV and Figure V. Comparison of both non obese groups revealed a significant difference in the mean age $(\mathrm{p} \leq 0.001)$, weight $(\mathrm{p} \leq 0.02)$, BMI $(\mathrm{p} \leq 0.01)$ and insulin $(\mathrm{p} \leq 0.05)$ between the two non-obese groups. There was also a significant difference in the mean age $(\mathrm{p} \leq 0.001)$, and triglyceride $(p \leq 0.001)$ between the two obese groups. Between the pre menopausal non-obese and obese groups, there was a significant difference in the mean age $(p \leq 0.001)$, weight $(p \leq 0.001)$ and BMI $(p \leq 0.001)$. Similarly, a significant difference in the mean weight $(\mathrm{p} \leq 0.001)$, BMI $(\mathrm{p} \leq 0.001)$, insulin $(\mathrm{p} \leq 0.01)$, leptin $(\mathrm{p} \leq 0.001)$ and HOMA IR $(\mathrm{p} \leq 0.02)$ between the postmenopausal non-obese and obese groups was observed.

Tables III and IV and figure VI, show the comparison of means of the four study groups with and without outliers. There is significant difference in the insulin $(p \leq 0.05)$ between the two non-obese groups. This difference becomes more significant $(\mathrm{p} \leq 0.01)$ when the outliers were removed. Between the two obese groups, there was no significant difference in the mean FSI, FSL and HOMA IR. However when outliers were removed the difference in mean FSI approached close to significance $(p \leq 0.06)$. Similarly, there was no significant difference in the mean FSI, FSL and HOMA IR between the two premenopausal groups. However when outliers were removed the difference became significant FSI $(\mathrm{p} \leq 0.02)$, FSL $(\mathrm{p} \leq 0.001)$ and HOMA IR $(\mathrm{p} \leq 0.04)$ between the pre menopausal non-obese and obese groups. Comparison of postmenopausal non-obese and obese groups revealed a significant difference in the mean FSI $(p \leq 0.01)$, FSL $(p \leq 0.001)$ and HOMA IR $(p \leq 0.02)$ between the postmenopausal non-obese and obese groups with outliers. When analyzed without outliers, the difference in mean FSI $(p \leq 0.001)$ and HOMA IR $(p \leq 0.001)$ becomes more significant. The difference in mean FSL $(p \leq 0.001)$ remains same as without outliers.

\subsection{Correlations of Leptin}

Leptin has significant positive correlation with weight, BMI, Insulin and HOMA IR. Figure VII, VIII, IX and X shows scattergrams depicting the correlation of leptin and weight, leptin and BMI, leptin and insulin and leptin and HOMA IR respectively.

\subsection{Correlations of Insulin}

Insulin has significant positive correlation with weight, leptin and HOMA IR. Figure XI, XII and XIII shows scattergrams depicting the correlation of insulin and weight, insulin and leptin and insulin and HOMA IR respectively.

\section{Discussion}

Compared to men, many women before the age of menopause are partly protected from coronary heart disease. As women age, their risk of heart disease rises. Coronary heart disease rates in women after menopause are 2-3 times higher than in women of the same age before menopause.

The reasons for the lower incidence of coronary heart disease in younger women are not clear. The loss of natural estrogen as women age may contribute; however, in light of recent results from clinical trials, the American Heart Association does not advise women to take postmenopausal hormone therapy (PHT, formerly called hormone replacement therapy or HRT) to reduce the risk of coronary heart disease. Researchers reported 
an increase in coronary heart disease (CHD) events among women taking HRT during the first year of treatment compared with those on placebo. Whether longer follow-up might show significant benefit is still not clear (Mosca et al., 2002).

Another additional factor that further accentuates the risk of CAD in postmenopausal women, is obesity. High blood levels of triglycerides may be a particularly important risk factor in women and the elderly. Regular physical activity and a healthy weight reduce the risk of type 2 diabetes, which appears to be an even stronger contributing risk factor for heart disease in postmenopausal women than in men (American Heart Association). It has also been found that estrogen suppresses appetite using the same pathways in the brain as leptin, leading the way to a viable approach to tackling obesity in people resistant to leptin. So use of PHT in postmenopausal obese women is still questionable (Guo et al., 2001).

\subsection{Fasting Blood Sugar (FBS)}

In this study the frequency distribution of using chi square test revealed that postmenopausal women had higher levels, and among postmenopausal women, obese had higher levels than nonobese. When mean between groups was compared using t test, obese postmenopausal women had higher levels of ; however this difference was not statistically significant. These findings are consistent with previous studies as hyperglycemia, hypertriglyceridemia, hyperinsulinemia / insulin resistance, and obesity are inter-related.

\subsection{Fasting Triglyceride (FTG)}

There was no significant difference in the frequency distribution of triglyceride using chi square test. When mean FTG was compared between groups it was revealed that obese postmenopausal women had higher level as compared to obese premenopausal $(\mathrm{P}<0.001)$.

\subsection{Fasting Serum Insulin (FSI)}

Frequency distribution of FSI shows marked positive skewness (3.27) and leptokurtosis (11.55). When data were analyzed for the cause of this skewness outliers were identified. So the data were analyzed with and without outliers. The distribution became almost normal (skewness 0.6) with platykurtosis $(0.2)$ when the outliers were removed. The mean FSI was also compared between the groups, with and without outliers. When the whole data (including outliers) were analyzed, there was significant difference in mean FSI between both non-obese groups $(p=0.05)$, and between postmenopausal obese and non-obese groups $(p=0.01)$. When data were analyzed without outliers this difference persisted and the level of significance increased i.e., mean FSI between both non-obese groups $(\mathrm{p}=0.01)$, and between postmenopausal obese and non-obese groups $(\mathrm{p}=0.001)$. Moreover the difference between both obese groups almost approached statistical significance $(p=0.06)$, and the difference between premenopausal non-obese and obese $(\mathrm{p}=0.02)$ also became evident. The data were also analyzed for correlations of insulin with various parameters. A significant positive correlation was seen with weight $(\mathrm{r}=0.23 ; \mathrm{p}<0.05)$, leptin $(\mathrm{r}=0.30 ; \mathrm{p}<0.01)$ and HOMA IR $(\mathrm{r}=0.99 ; \mathrm{p}<0.01)$. This is also in harmony with previous studies (Thomas et al., 2000; Guven et al., 1999; Havel et al., 1996; Ryan et al., 2000; Doucet et al., 2000).

\subsection{Fasting Serum Leptin (FSL)}

Frequency distribution of leptin also shows positive skewness (1.85) and leptokurtosis (5.4). Outliers are present, the analysis of data without outliers leads to platykurtosis (0.9) and slight decrease in skewness (1.06). Outliers are present in the non-obese premenopausal group so that there is no change in mean FSL of obese premenopausal, non-obese postmenopausal and obese postmenopausal, with and without outliers. However the mean FSL of non-obese premenopausal is decreased when outliers are removed; and the difference in mean FSL between premenopausal non-obese and obese becomes significant $(\mathrm{p}<0.001)$. Postmenopausal obese have higher mean FSL level as compared to postmenopausal non-obese $(p<0.001)$, with and without outliers. The data were also analyzed for correlations of leptin. Significant positive correlation was found between leptin and weight ( $r$ $=0.46 ; \mathrm{p}<0.01)$, BMI $(\mathrm{r}=0.46 ; \mathrm{p}<0.01)$, insulin $(\mathrm{r}=0.30 ; \mathrm{p}<0.01)$ and HOMA IR $(\mathrm{r}=0.30 ; \mathrm{p}<0.01)$. This is in concordance with previous studies (Thomas et al., 2000; Guven et al., 1999; Havel et al., 1996; Ryan et al., 2000; Doucet et al., 2000).

\subsection{Homeostatic Insulin Resistance Index (HOMA IR)}

Frequency distribution of HOMA IR shows marked positive skewness (3.58) and leptokurtosis (13.82). When data were analyzed for the cause of this skewness outliers were identified. So the data were analyzed with and without outliers. The distribution became almost normal (skewness 1.0) with platykurtosis (1.2) when the outliers were removed. The mean HOMA IR was also compared between the groups, with and without outliers. When the whole data (including outliers) were analyzed, there was significant difference in mean HOMA IR between postmenopausal non-obese and obese $(p=0.02)$. When data were analyzed without outliers this 
difference persisted and the level of significance increased i.e, mean HOMA IR between postmenopausal non-obese and obese groups $(\mathrm{p}=0.001)$, and the difference between premenopausal obese and non-obese groups became significant $(\mathrm{p}=0.04)$. The data were also analyzed for correlations of HOMA IR with various parameters. A significant positive correlation was seen between HOMA IR and FSL $(r=0.30 ; p<0.01)$ and HOMA IR and FSI ( $\mathrm{r}=0.99 ; \mathrm{p}<0.01$ ). This is also in conformity with previous studies (Thomas et al., 2000; Guven et al., 1999; Havel et al., 1996; Ryan et al., 2000; Doucet et al., 2000).

These findings are in favour of the studies which show that menopause does not affect serum leptin levels. Our findings are in consistence with majority of studies done worldwide (Rosenbaum et al., 1996; Summer et al., 1998; Hadji et al., 2000; Perry et al., 1997; Ahren et al., 1998; Castracane et al., 1998; Considine et al., 1996; Douchi et al., 2002; Doucet et al., 2000). Our results differ from those who believe that premenopausal women have higher FSL levels than postmenopausal (Hayase et al., 2002; Ayub et al., 2006; Ostlund et al., 1996; Isidori et al., 2000; Shimizu et al., 1997; Ryan et al., 2000) or those who suppose that FSL levels are higher in postmenopausal (Gomez et al., 2003; Baumgartner et al., 1999). In both obese groups mean FSL is higher than both non-obese groups, which supports the positive correlation of leptin with BMI and weight. Mean FSI is also higher in both obese groups compared with non-obese, this is also in concordance with the positive correlation of insulin with weight (Thomas et al., 2000; Guven et al., 1999; Havel et al., 1996; Ryan et al., 2000; Doucet et al., 2000).

Limitations: The sample size was small in this study. The reason being inability to find absolutely healthy postmenopausal women and secondly; Diabetes, hypertension and heart disease are quite prevalent among Pakistani postmenopausal women, which led to the exclusion of many subjects from the study when they underwent screening history, examination and tests.

\section{Conclusions}

Following conclusions have been drawn from the study:

1) Menopause does not influence FSL levels.

2) The variations observed in FSL levels between pre and postmenopausal women, in some studies, might be due to differences in their mean FSI levels and BMI.

3) The mean FSL tends to increase with increased BMI irrespective of menopausal status.

4) There is corresponding increase in FSL with increase in FSI levels, generally the obese have higher FSI and FSL levels, irrespective of menopausal status.

5) The major metabolic hormones insulin and leptin, don't seem to have a role in pathophysiology of postmenopausal obesity.

\section{References}

Ahren, B.O., \& Pacini, G. J. (1998). Clin Endocrinol Metab, 83. 3350-3356.

Ayub, N., Khan, S.R., \& Syed, F. (2006). Leptin levels in pre and post menopausal Pakistani women. J Pak Med Assoc, 56, 3-5.

Baumgartner, R.N., Ross, R.R., Waters, D.L., Brooks, W.M., Morley, J.E., Montoya, G.D., \& Garry, P.J. (1999). Serum leptin in elderly peoplr: associations with sex hormones, insulins and adipose tissue volumes. Obes Res, 7 , 141-149.

Bhansali, A., Nagaprasad, G., Agarwal, A., Dutta, P., \& Bhadada, S. (2006). Does body mass index predict overweight in native Asian Indians? A study from North Indian population. Ann Nutr Metab, 50, 66-73.

Castracane, V.D., Kraemer, R.R., Franken, M.A., Kraemer, G.R., \& Gimpel, T. (1998). Serum leptin concentration in women: effect of age, obesity and estrogen administration. Fertil Steril, 70, 472-477.

Champe, P.C., Harvey, R.A., \& Ferrier, D.R. (1994). Lippincott's Illustrated Reviews: Biochemistry. Lippincott Williams \& Wilkins, Philadelphia, 350-351.

Considine, R.V., Sinha, M.K., Heiman, M.L., Kriaugiunas, A., Stephens, T.W., Nyce, M.R., Ohannesian, J.P., Marco, C.C., McKee, L.J., Bauer, T.L., \& Caro, J.F. (1996). Serum Immunoreactive-Leptin Concentrations in Normal- Weight and Obese Humans. N Engl J Med, 334, 292- 295.

Doucet, E., St Pierre, S., Almeras, N., Mauriege, P., Despres, J.P., Richard, D., Bouchard, C., \& Tremblay, A. (2000). Fasting Insulin Levels Influence Plasma Leptin Levels Independently from the Contribution of Adiposity: Evidence from Both a Cross-Sectional and an Intervention Study. J Clin Endocrinol Metab, 85, 4231-4237. 
Douchi, T., Iwamoto, I., Yoshimitsu, N., Kosha, S., \& Nagata, Y. (2002). Leptin production in pre and postmenopausal women. Maturitas, 42, 210-223.

Gomez, J.M., Maravall, F.J., Gomez, N., Navarro, M.A., Casamitjana, R., \& Soler, J. (2003). Interactions between serum leptin, the insulin-like growth factor-I system, and sex, age, anthropometric and body composition variables in a healthy population randomly selected. Clin Endocrinol, 58, 213-219.

Guo, X., Chen, S., \& Xing, F. (2001). Effects of leptin on estradiol and progesterone production by human luteinized cells in vitro. Zhonghua Fa Chan Ke Za Zhi, 36, 95-97.

Guven, S., El-Bershawi, A., Gabriele, E.S., Charles, R.W., Hoffmann, R.G., Krakower, G.R., \& Kissebah, A.H. (1999). Plasma leptin and insulin levele in weight-reduced obese women with normal body mass index relationships with body composition and insulin. Diabetes, 48, 347-352.

Hadji, P., Hars, O., Bock, K., Sturm, G., Bauer, T., Emons, G., Schulz, K.D. (2000). The influence of menopause and body mass index on serum leptin concentrations. Eur J Endocrinol, 143, 55-60.

Havel, P.J., Kasim, K.S., Mueller, W., Johnson, P.R., Gingerich, R.L., \& Stern, J.S. (1996). Relationship of plasma leptin to plasma insulin and adiposity in normal weight and overweight women: effects of dietary fat content and sustained weight loss. J Clin Endocrinol Metab, 81, 4406-4413.

Hayase, H., Nomura, S., Abe, T., \& Izawa, T. (2002). Relations between fat distributions and several plasma adipocytokines after exercise training in premenopausal and postmenopausal women. $J$ Physiol Anthropol Appl Human Sci, 21, 105-113.

Injuin, H., Douchi, T., Oki, T., Maruta, K., \& Nagata, Y. (1999). The contribution of menopause to changes in body-fat distribution. J Obstet Gynaecol Res, 1999, 25, 367-372.

Isidori, A.M., Strollo, F., More, M., Caprio, M., Aversa, A., Moretti, C., Frajese, G., Riondino, G., \& Fabbri, A. (2000). Leptin and Ageing: Correlation with Endocrine Changes in Male and Female Healthy Adult Populations of Different Body Weights. J Clin Endocrinol Metab, 85, 1954-1962.

Jaleel, F., Jaleel, A., Rehman, M. A., \& Alam, E. (2006). Comparison of adiponectin, leptin and blood lipid levels in normal and obese postmenopausal women. J Pak Med Assoc, 56, 391-394.

Mosca, L. (2002). Response to Heart and Estrogen-Progestin Replacement Study Follow-up (HERS II). JAMA, 288, 49-57.

Ostlund, R.E.Jr., Yang, J.W., Klein, S., \& Gingerich, R. (1996). Relation between plasma leptin concentration and body fat, gender, diet, age, and metabolic covarities. J Clin Endocrinol Metab, 81, 3909-3913.

Perry, H.M.3 ${ }^{\text {rd }}$., Morley, J.E., Horowitz, M., Kaiser, F.E., Miller, D.K., \& Wittert, G. (1997). Body composition and age in African-American and Caucasian women: relationship to plasma leptin levels. Metabolism, 46, 1399-1405.

Rosenbaum, M., Nicolson, M., Hirsch, J., Heymsfield, S.B., Gallagher, D., Chu, F., Leibel, R.L. (1996). Effects of gender, body composition and menopause on plasma concentrations of leptin. $J$ Clin Endocrinol Metab, 81, 3424-3427.

Ryan, A.S., Pratley, R.E., Elahi, D., \& Goldberg, A.P. (2000). Changes in plasma leptin and insulin action with resistive training in postmenopausal women. Int J Obes Relat Metab Disord, 24, 27-32.

Shimizu, H., Shimomura, Y., Nakanishi, Y., Futawatari, T., Ohtani, K., Sato, N., \& Mori, M. (1997). Estrogen increases in vivo leptin production in rats and human subjects. $J$ Endocrinol, 154, $285-292$.

Sumner, A.E., Falkner, B., Kushner, H., \& Considine, R.V. (1998). Relationship of leptin concentrations to gender, menopause, age, diabetes, and fat mass in African Americans. Obes Res, 6, 128-133.

Thomas, T., Berguera, B., Melton, L.J 3rd., Atkinson, E.J., O’Fallon, W.M., Riggs, B.L., \& Khosla, S. (2000). Relationship of serum leptins levels with body composition and sex steroids and insulin levels in men and women. Metabolism, 49, 1278-1284. 
Table 1. Means and \pm SD of demographic variables of four study groups

\begin{tabular}{|c|c|c|c|c|c|c|c|c|}
\hline \multirow{2}{*}{ Variables } & \multicolumn{2}{|c|}{$\begin{array}{c}\text { Non-obese } \\
\text { Premenopausal }\end{array}$} & \multicolumn{2}{|c|}{$\begin{array}{c}\text { Obese } \\
\text { Premenopausal }\end{array}$} & \multicolumn{2}{|c|}{$\begin{array}{c}\text { Non-obese } \\
\text { Postmenopausal }\end{array}$} & \multicolumn{2}{|c|}{ Obese Postmenopausal } \\
\hline & Mean & \pm SD & Mean & \pm SD & Mean & \pm SD & Mean & \pm SD \\
\hline Age (years) & 26.6 & 7.07 & $34.9 *$ & 6.38 & 57.58 & 11.51 & 52.83 & 8.19 \\
\hline $\begin{array}{c}\text { Height } \\
\text { (meters) }\end{array}$ & 1.55 & & 1.53 & & 1.53 & & 1.51 & \\
\hline $\begin{array}{c}\text { Weight } \\
\text { (kgs) }\end{array}$ & 49.6 & 6.09 & $72.8 * *$ & 9.98 & $54.3 * * * *$ & 5.89 & $71.2 * * * * * *$ & 11.0 \\
\hline $\begin{array}{c}\text { BMI } \\
\left(\mathrm{kg} / \mathrm{m}^{2}\right)\end{array}$ & 20.6 & 2.91 & $30.7 * * *$ & 3.88 & $22.76 * * * * *$ & 1.44 & $30.79 * * * * * * *$ & 4.18 \\
\hline
\end{tabular}

$* \mathrm{p} \leq 0.001$ as compared to non-obese premenopausal $* * \mathrm{p} \leq 0.001$ as compared to non-obese premenopausal $* * * \mathrm{p} \leq 0.001$ as compared to non-obese premenopausal $* * * * \mathrm{p} \leq 0.02$ as compared to non-obese premenopausal $* * * * * \mathrm{p} \leq 0.01$ as compared to non-obese premenopausal $* * * * * * \mathrm{p} \leq 0.001$ as compared to non-obese postmenopausal $* * * * * * * \mathrm{p}<0.001$ as compared to non-obese postmenopausal

Table 2. Means and \pm SD of biochemical variables of four study groups

\begin{tabular}{|c|c|c|c|c|c|c|c|c|}
\hline \multirow{2}{*}{ Variables } & \multicolumn{2}{c|}{$\begin{array}{c}\text { Non-obese } \\
\text { Premenopausal }\end{array}$} & \multicolumn{2}{c|}{$\begin{array}{c}\text { Obese } \\
\text { Premenopausal }\end{array}$} & \multicolumn{2}{c|}{$\begin{array}{c}\text { Non-obese } \\
\text { Postmenopausal }\end{array}$} & \multicolumn{2}{|c|}{$\begin{array}{c}\text { Obese } \\
\text { Postmenopausal }\end{array}$} \\
\cline { 2 - 8 } & Mean & \pm SD & Mean & \pm SD & Mean & \pm SD & Mean & \pm SD \\
\hline $\begin{array}{c}\text { FBS } \\
(\mathbf{m m o l} / \mathbf{l})\end{array}$ & 4.89 & .47 & 5.04 & .48 & 5.1 & .54 & 5.28 & .56 \\
\hline $\begin{array}{c}\text { FTG } \\
(\mathbf{m m o l} / \mathbf{l})\end{array}$ & 1.2 & .44 & 1.14 & .32 & 1.4 & .43 & $1.60 *$ & .57 \\
\hline
\end{tabular}

${ }^{*} \mathrm{p} \leq 0.001$ as compared to obese premenopausal 
Table 3. Comparison of mean fasting serum insulin (FSI), fasting serum leptin (FSL), homeostatic insulin resistance index (HOMA IR), of the four study groups with outliers

\begin{tabular}{|c|c|c|c|c|c|c|c|c|}
\hline \multirow{2}{*}{ Variables } & \multicolumn{2}{|c|}{$\begin{array}{c}\text { Non-obese } \\
\text { Premenopausal } \\
\end{array}$} & \multicolumn{2}{|c|}{$\begin{array}{c}\text { Obese } \\
\text { Premenopausal } \\
\end{array}$} & \multicolumn{2}{|c|}{$\begin{array}{c}\text { Non-obese } \\
\text { Postmenopausal } \\
\end{array}$} & \multicolumn{2}{|c|}{ Obese Postmenopausal } \\
\hline & Mean & \pm SD & Mean & \pm SD & Mean & \pm SD & Mean & \pm SD \\
\hline $\begin{array}{c}\text { FSI } \\
(\mu \mathrm{IU} / \mathrm{ml}) \\
\end{array}$ & 24.17 & 22.9 & 26.78 & 15.06 & $12.53 * * * *$ & 4.01 & $37.62 *$ & 40.58 \\
\hline $\begin{array}{c}\text { FSL } \\
(\mathrm{ng} / \mathrm{ml})\end{array}$ & 11.18 & 17.4 & 19.53 & 12.06 & 4.28 & 4.28 & $20.28^{* *}$ & 12.08 \\
\hline HOMA IR & 5.05 & 6.14 & 5.98 & 3.44 & 2.89 & 1.00 & $8.65^{* * *}$ & 9.58 \\
\hline
\end{tabular}

$* \mathrm{p} \leq 0.01$ as compared to non-obese postmenopausal

$* * \mathrm{p} \leq 0.001$ as compared to non-obese postmenopausal

$* * * \mathrm{p} \leq 0.02$ as compared to non-obese postmenopausal

$* * * * \mathrm{p} \leq 0.05$ as compared to non-obese premenopausal

Table 4. Comparison of mean fasting serum insulin (FSI), fasting serum leptin (FSL), homeostatic insulin resistance index (HOMA IR), of the four study groups without outliers

\begin{tabular}{|c|c|c|c|c|c|c|c|c|}
\hline \multirow{2}{*}{ Variables } & \multicolumn{2}{|c|}{$\begin{array}{c}\text { Non-obese } \\
\text { Premenopausal }\end{array}$} & \multicolumn{2}{|c|}{$\begin{array}{c}\text { Obese } \\
\text { Premenopausal } \\
\end{array}$} & \multicolumn{2}{|c|}{$\begin{array}{c}\text { Non-obese } \\
\text { Postmenopausal } \\
\end{array}$} & \multicolumn{2}{|c|}{ Obese Postmenopausal } \\
\hline & Mean & \pm SD & Mean & \pm SD & Mean & \pm SD & Mean & \pm SD \\
\hline $\begin{array}{c}\text { FSI } \\
(\mu \mathrm{IU} / \mathrm{ml})\end{array}$ & 17.92 & 7.72 & $23.83^{*}$ & 7.49 & $12.53 * * * *$ & 4.01 & $19.59 * * * * *$ & 6.37 \\
\hline $\begin{array}{c}\text { FSL } \\
(\mathbf{n g} / \mathbf{m l})\end{array}$ & 7.55 & 6.55 & $19.53^{* *}$ & 12.06 & 4.28 & 4.28 & $20.28 * * * * * * *$ & 12.08 \\
\hline HOMA IR & 4.23 & 2.36 & $5.28 * * *$ & 1.55 & 2.89 & 1.00 & $5.04 * * * * * *$ & 2.14 \\
\hline
\end{tabular}

${ }^{*} \mathrm{p} \leq 0.02$ as compared to non-obese premenopausal

$* * \mathrm{p} \leq 0.001$ as compared to non-obese premenopausal

$* * * \mathrm{P} \leq 0.04$ as compared to non obese premenopausal

$* * * * \mathrm{p} \leq 0.01$ as compared to non-obese premenopausal

$* * * * * \mathrm{p} \leq 0.001$ as compared to non-obese postmenopausal

$* * * * * * \mathrm{p} \leq 0.001$ as compared to non-obese postmenopausal

$* * * * * * * \mathrm{p} \leq 0.0001$ as compared to non-obese postmenopausal 

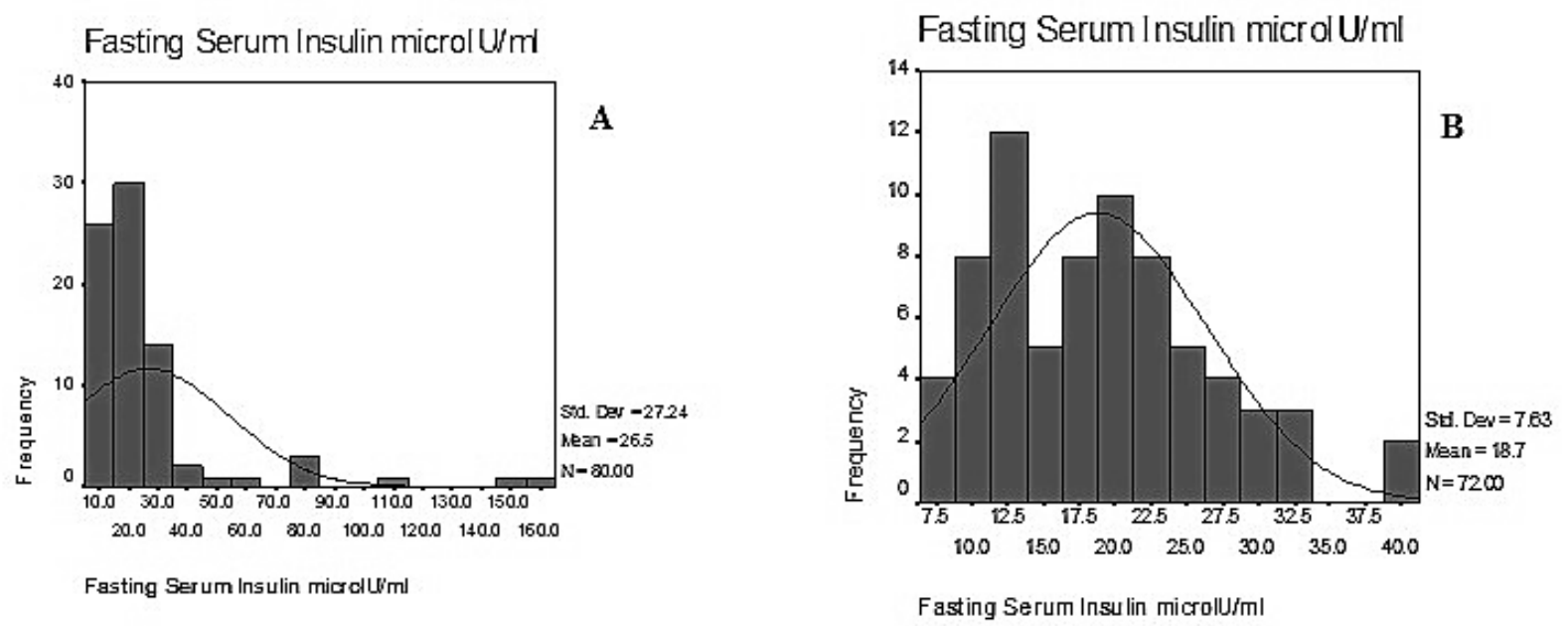

Figure I: Histogram showing serum insulin distribution with (A) and without (B) outliers
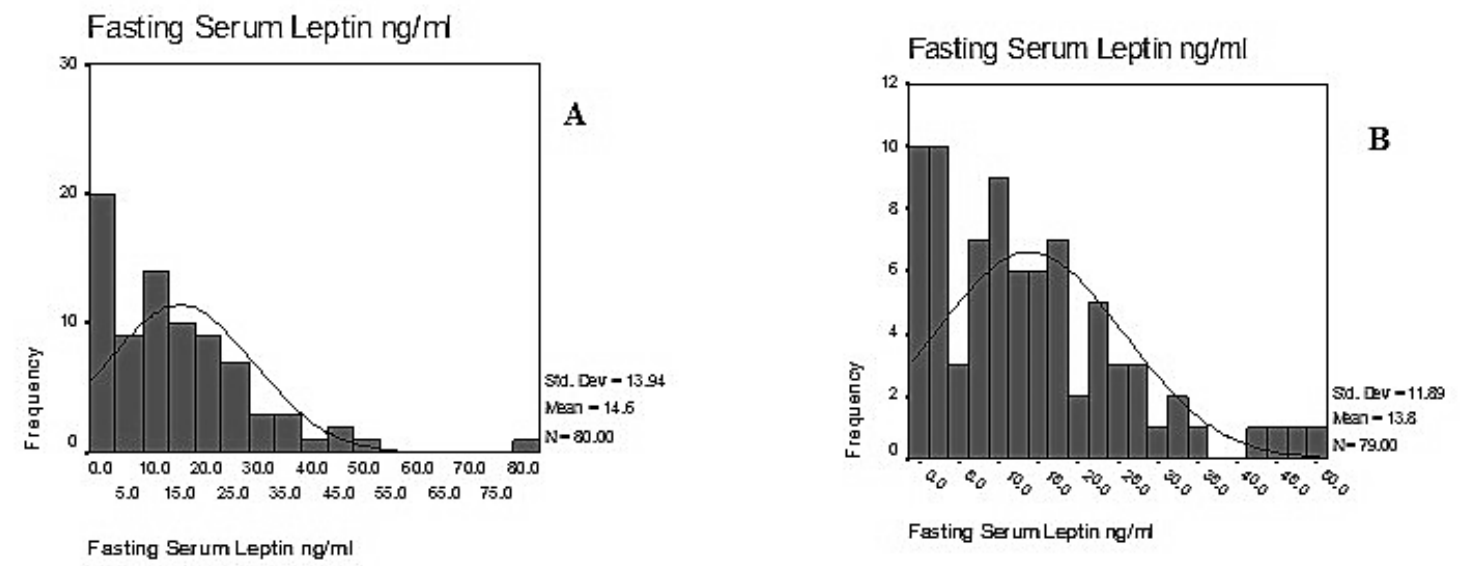

Figure II: Histogram showing serum leptin distribution with (A) and without (B) outliers 


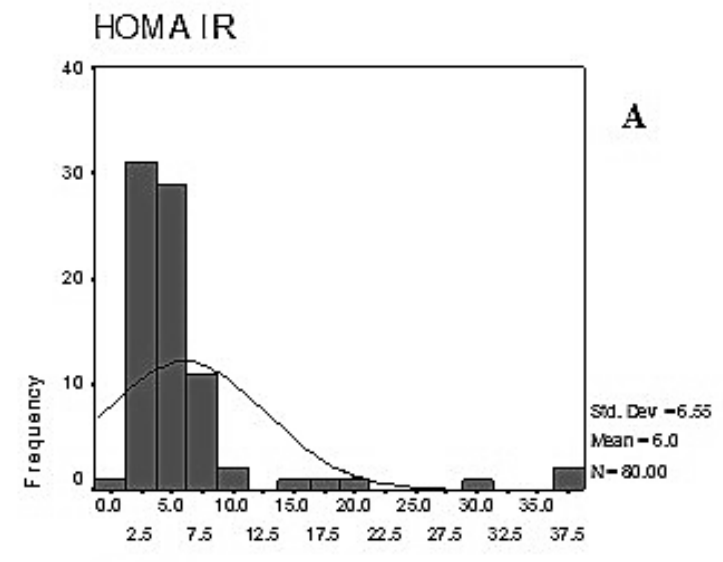

HOMA IR

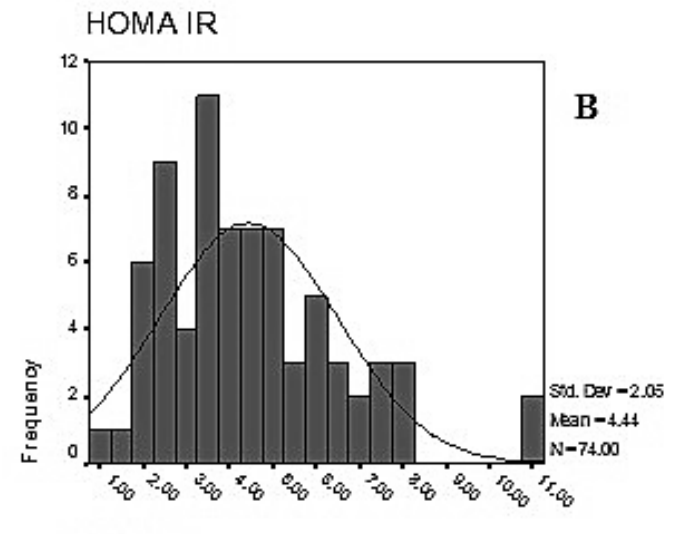

HOMA IR

Figure III: Histogram showing distribution of HOMA IR with (A) and without (B) outliers

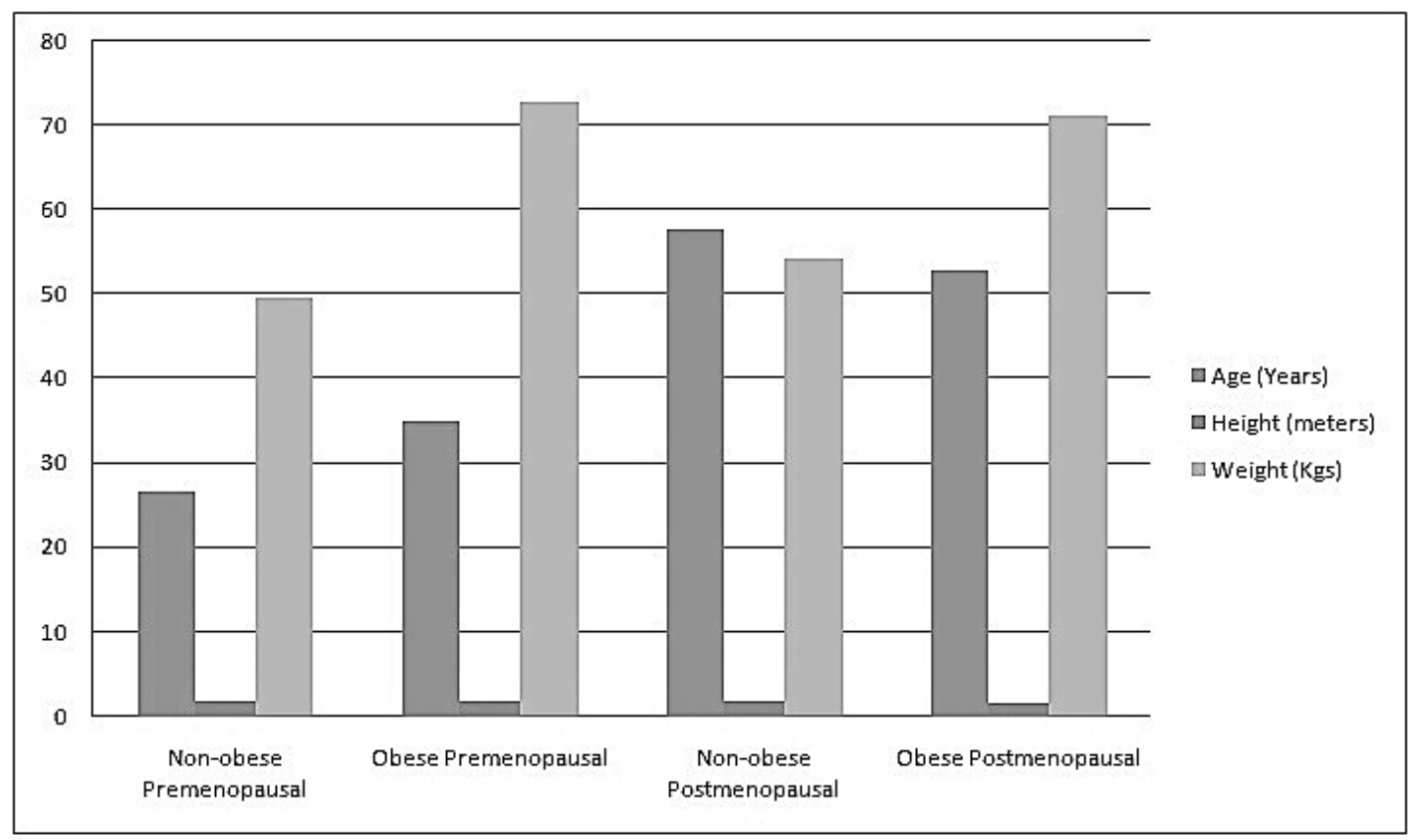

Figure IV: Comparison of mean age, height and weight of the four study groups 


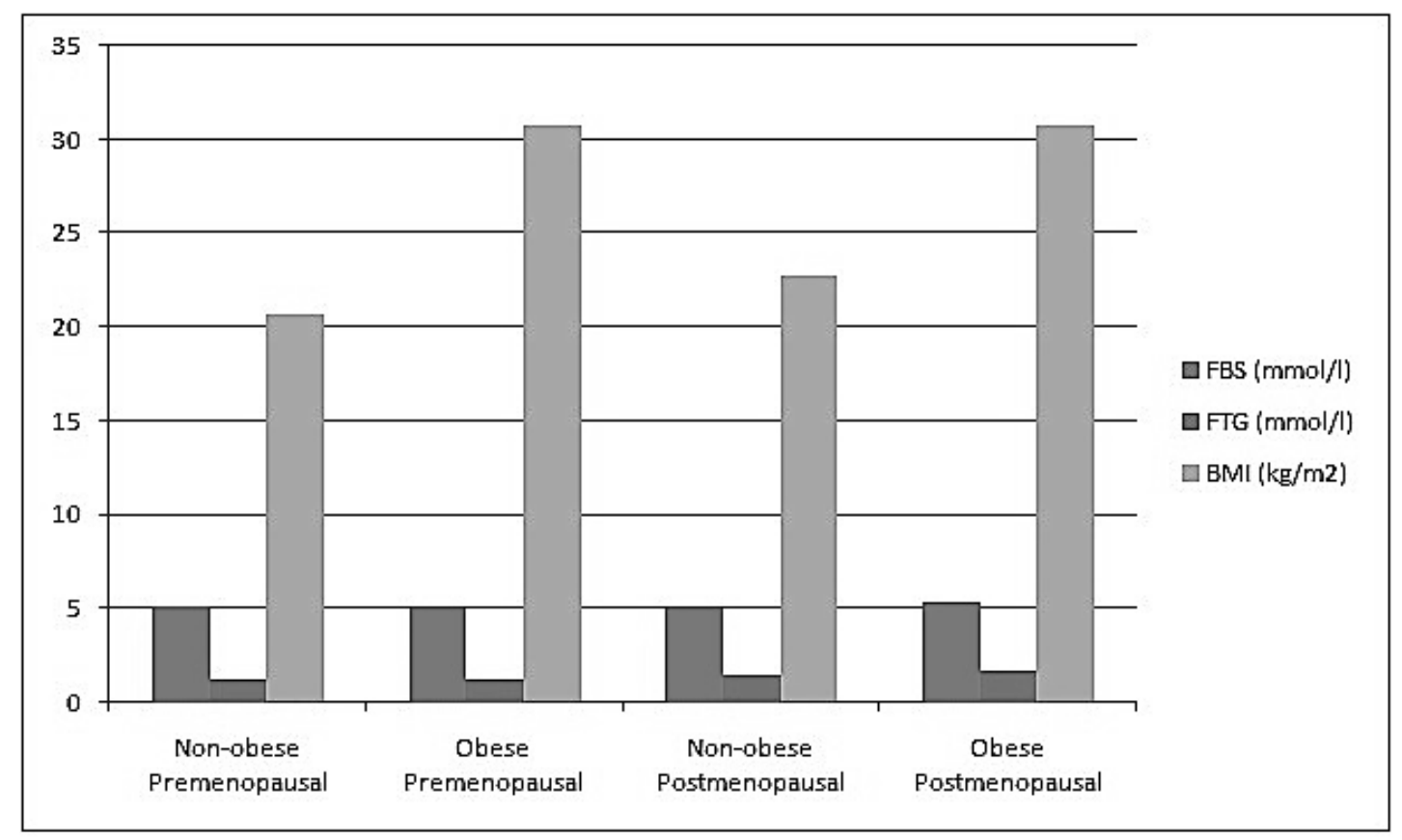

Figure V: Comparison of mean FBS, FTG and BMI of the four study groups
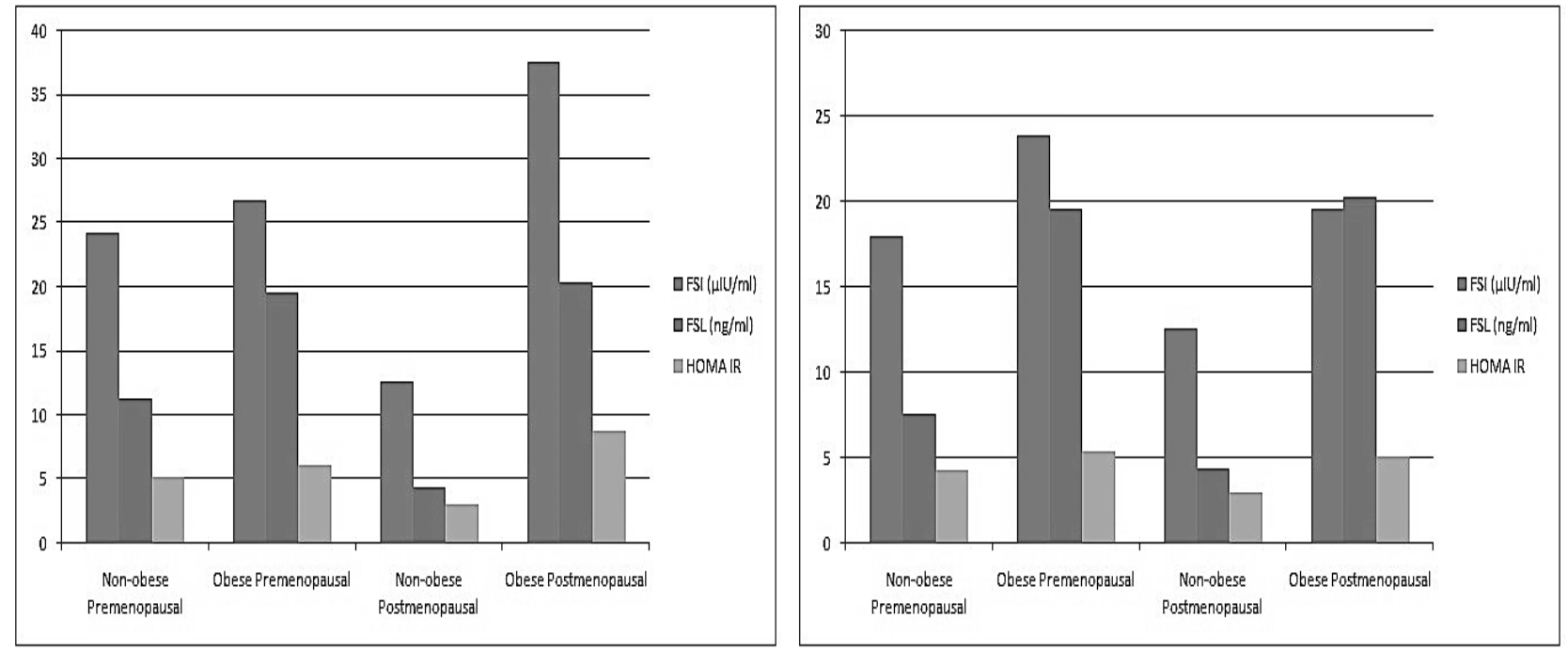

Figure VI: Comparison of mean FSI, FSL and HOMA R of the four study groups with (A) and without (B) outliers. 


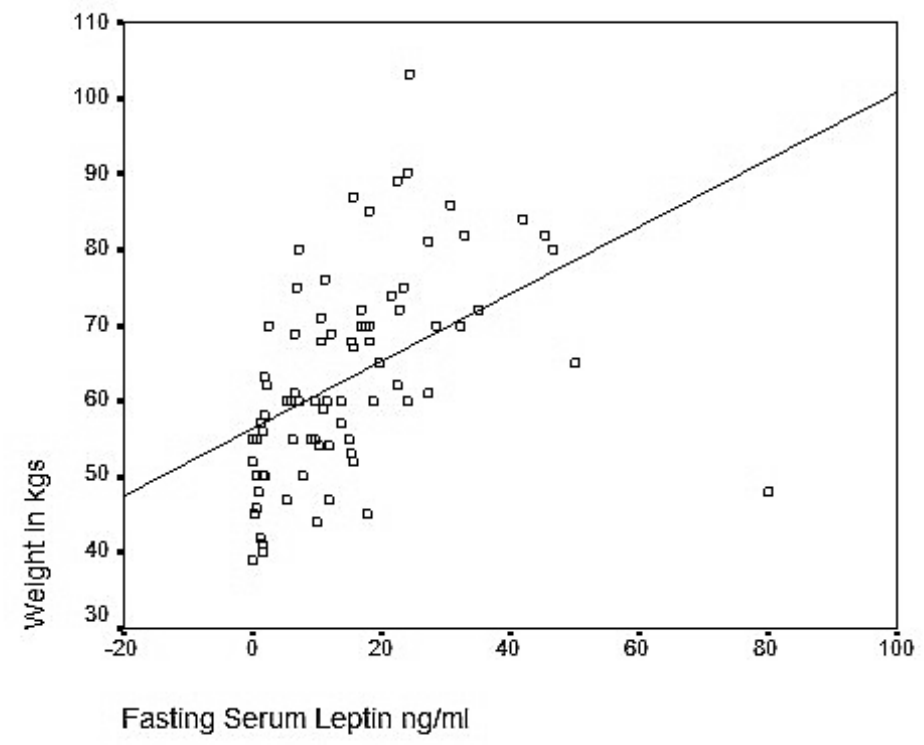

Figure VII: Scattergram showing correlation between fasting serum leptin and weight. Correlation is significant at the 0.01 level (2-tailed). $r=0.46$

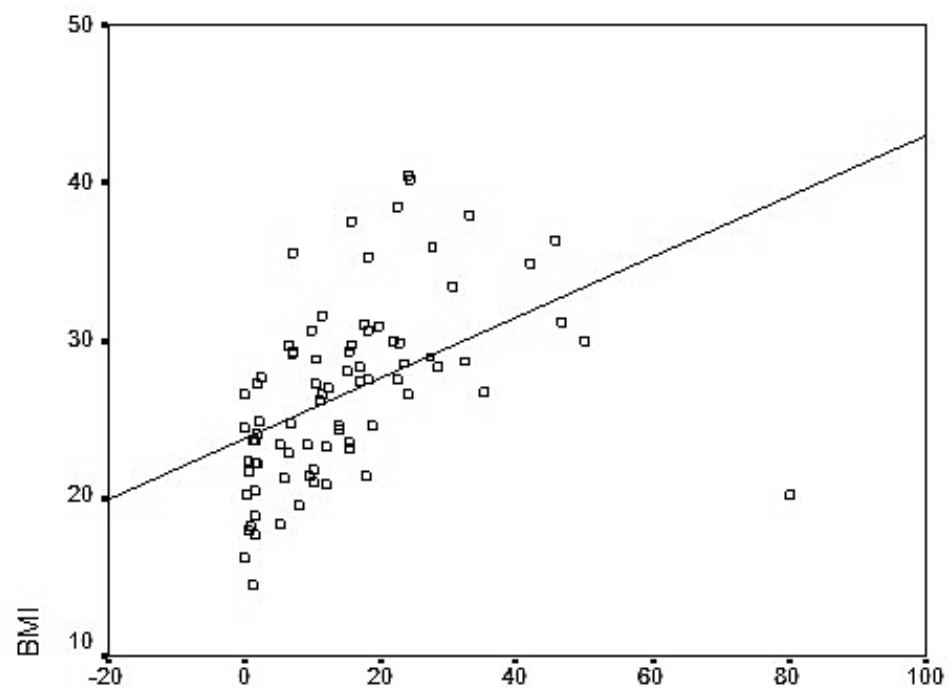

Fasting Serum Leptin ng/ml

Figure VIII: Scattergram showing correlation between fasting serum leptin and BMI.

Correlation is significant at the 0.01 level ( 2 -tailed). $r=0.46$ 


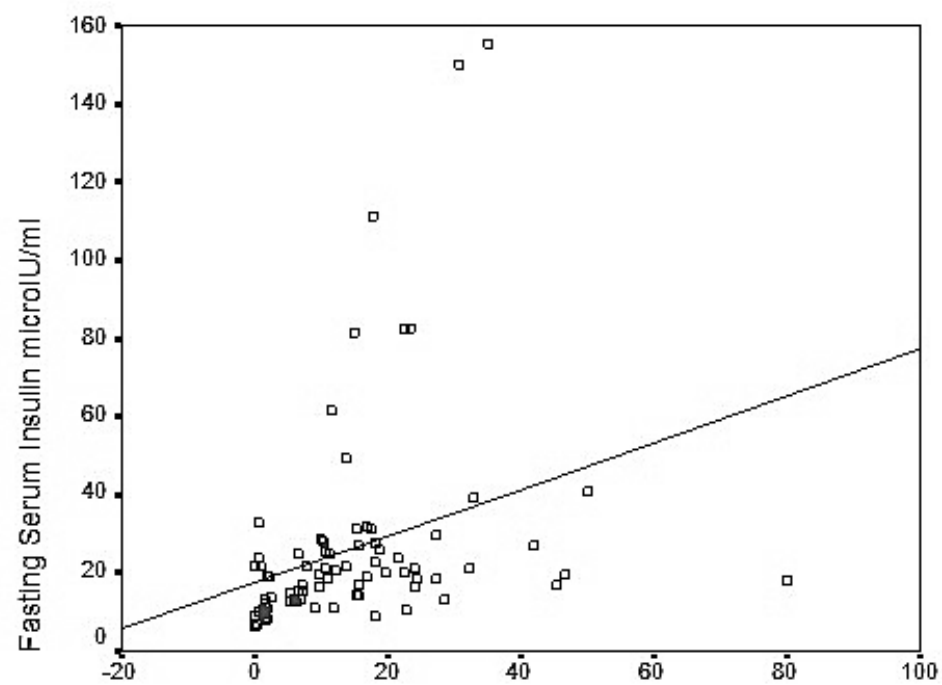

Fasting Serum Leptin ng/ml

Figure IX: Scattergram showing correlation between fasting serum leptin and insulin. Correlation is significant at the 0.01 level (2-tailed). $r=0.30$

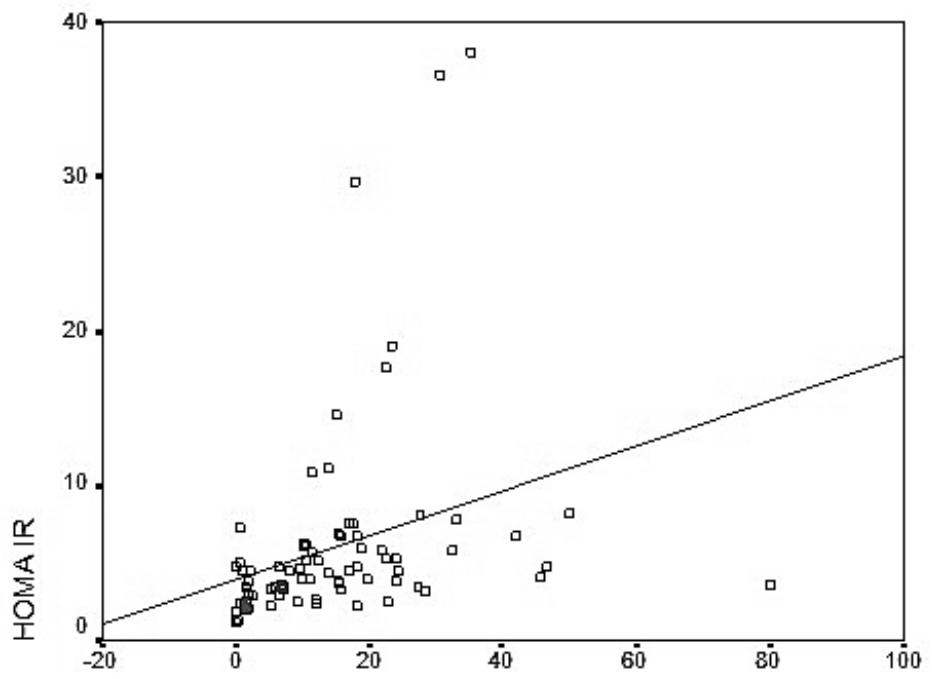

Fasting Serum Leptin ng/ml

Figure X: Scattergram showing correlation between fasting serum leptin and HOMA

IR. Correlation is significant at the 0.01 level (2-tailed). $r=0.30$ 


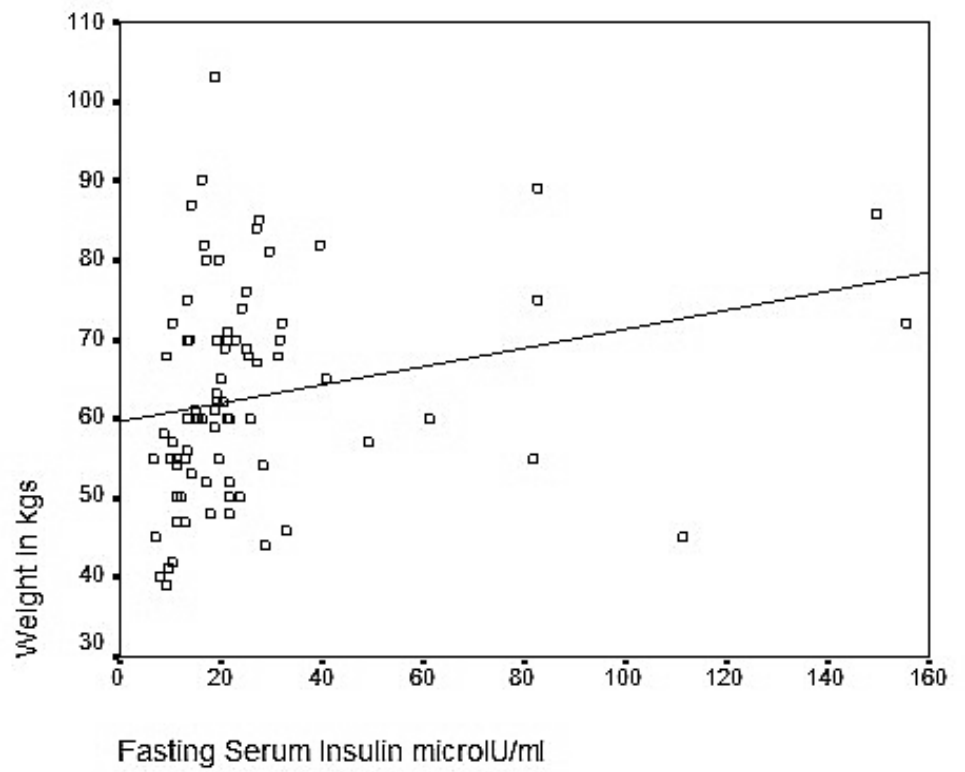

Figure XI: Scattergram showing correlation between fasting serum insulin and weight. Correlation is significant at the 0.05 level (2-tailed). $r=0.23$

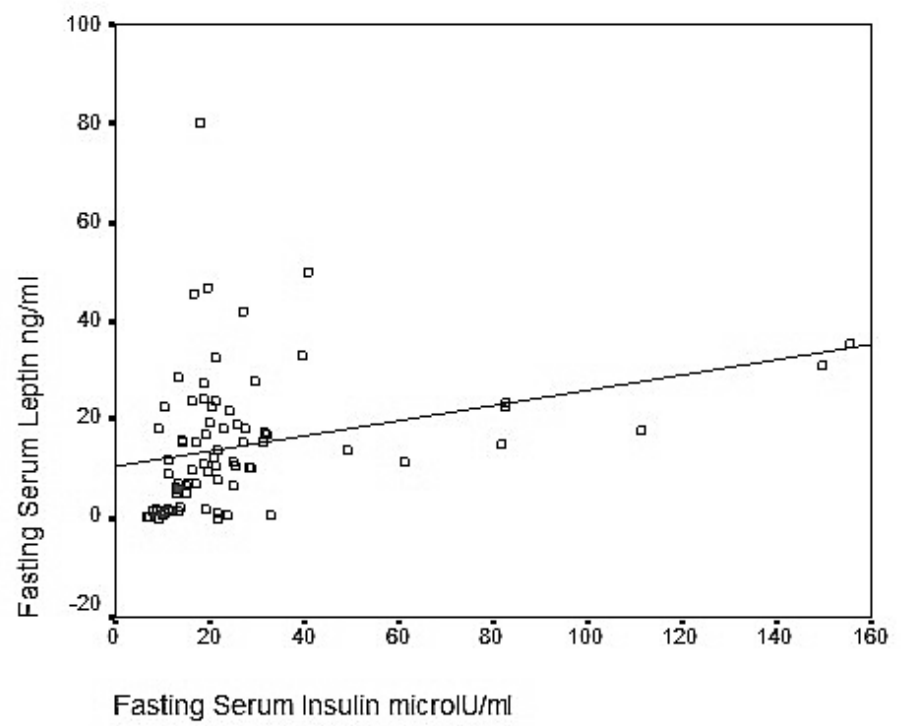

Figure XII: Scattergram showing correlation between fasting serum insulin and leptin. Correlation is significant at the 0.01 level (2-tailed). $r=030$ 


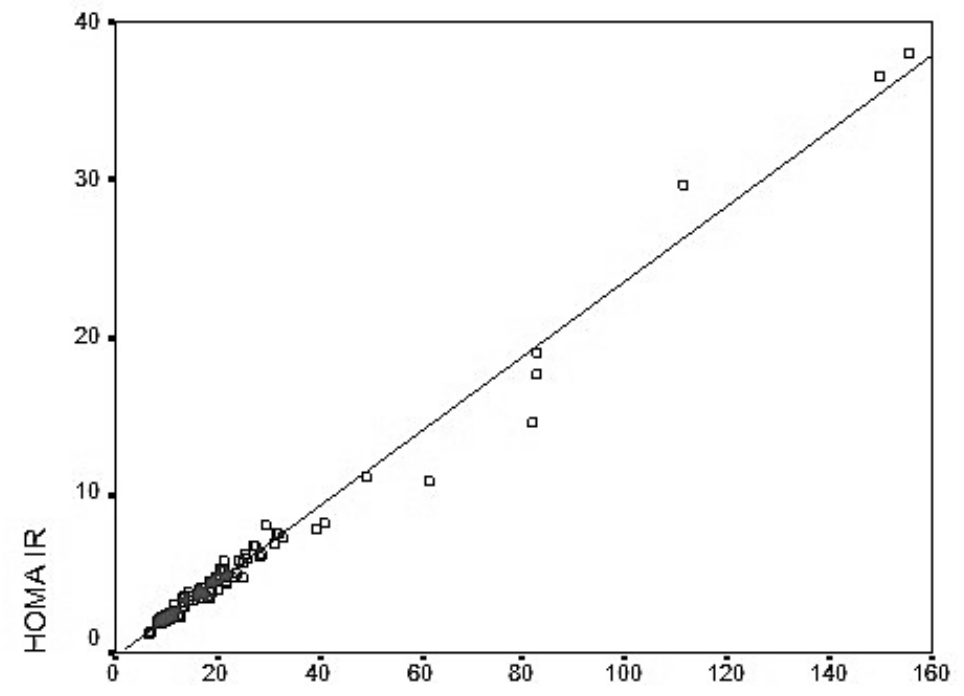

Fasting Serum Insulin microlU/ml

Figure XIII: Scattergram showing correlation between fasting serum insulin and HOMA IR. Correlation is significant at the 0.01 level (2-tailed). $r=0.99$ 